\title{
Importação de Técnicas de Recursos Humanos: problema ou solução?
}

\author{
Alexandre Santos ${ }^{1}$ \\ Rafael Diogo Pereira ${ }^{2}$ \\ Daniel Calbino ${ }^{3}$ \\ Thiago Duarte Pimentel ${ }^{4}$
}

\section{Resumo}

Partindo da premissa que a literatura brasileira de uma forma geral, mas principalmente na área de Recursos Humanos, é baseada em autores estrangeiros, o objetivo deste ensaio teórico é incitar uma reflexão sobre a eficiência da utilização de técnicas importadas de gestão de pessoas no Brasil. As indagações giram em torno da diferença entre contextos socioculturais e as implicações da adoção da base estrangeira (estereótipo de seu berço) no contexto brasileiro, onde o jeitinho brasileiro é considerado único e exclusivo. Esse ambiente acontece com o "patrimonialismo" como palco. Recorre-se também a possibilidade da tropicalização destes modelos pela vertente do isomorfismo. Contudo, conclui-se que as diferenças contextuais e socioculturais levam as técnicas de importação de gestão a serem pouco efetivas no Brasil.

Palavras-chave: Recursos Humanos. Importação de modelos gestão. Tropicalização. Isomorfismo.

\section{Introdução}

O uso de técnicas importadas de Gestão de Pessoas no Brasil se apresenta como uma espécie de paradigma, que serve de legitimação e solução de problemas diante da crença de que "bom" e "moderno" é gerado

\footnotetext{
${ }^{1}$ Mestre em Administração pela UFMG. Doutorando em Administração pela UFMG. Endereço: Universidade Federal de Minas Gerais. Avenida Antônio Carlos, 6627, CEP: 31270-901 - Belo Horizonte, MG -Brasil.E-mail: mralexandresantos@gmail.com.

${ }^{2}$ Mestre em Administração pela UFMG. Doutorando em Administração pela UFMG. Endereço: Universidade Federal de Minas Gerais. Avenida Antônio Carlos, 6627, CEP: 31270-901 - Belo Horizonte, MG - Brasil. E-mail: rdp@cepead.face.ufmg.br.

${ }^{3}$ Mestre em Administração pela UFMG. Doutorando em Administração pela UFMG. Endereço: Universidade Federal de Minas Gerais. Avenida Antônio Carlos, 6627, CEP: 31270-901 - Belo Horizonte, MG - Brasil.E-mail: dcalbino@yahoo.com.br.

${ }^{4}$ Mestre em Administração pela UFMG. Doutorando em Administração pela Universidade Federal de Lavras. Professor Assistente pela Universidade Federal de Juiz de Fora. Endereço: Universidade Federal de Lavras. DAE/UFLA. Campus Universitário. CEP: $37200-000$ Lavras, MG - Brasil-Caixa-Postal: 37.E-mail: tduartepimentel@yahoo.com.br.
} 
no primeiro mundo; caso contrário é anacrônico (SERVA, 1992). Nesse sentido, Tonelli e Caldas (2004) apregoam que a fonte de inspiração do $\mathrm{RH}$, assim como de outras áreas no mundo acadêmico brasileiro, é o estrangeiro. Consoante com esses autores, Vergara e Pinto (2001), em seu estudo sobre a nacionalidade dos autores referenciados na literatura brasileira, demonstram que esta literatura é baseada em autores estrangeiros e, além disso, que o uso da "importação de autores" vem aumentando. No ambiente dos gestores, Motta et al. (2000) dizem haver valorização de modelos organizacionais, metodologias e teorias geradas externamente - os autores defendem, inclusive, que o valor dado é em demasia e que não há preocupação com a funcionalidade desses modelos em nossa realidade.

Desse ambiente emergem algumas inquietações: quais as possíveis consequências da aplicação, em organizações, de técnicas importadas de gestão, ou, mais especificamente, de modelos estrangeiros de $\mathrm{RH}$ para administração de pessoal que não foram construídos tendo como base o ambiente sociocultural brasileiro? Qual o grau de eficiência dessas técnicas, ou modelos, aplicados nas empresas? Funcionariam? Conceberiam

soluções, ou gerariam problemas? Nota-se que é um momento pertinente para se refletir sobre a eficácia de tais técnicas e suas implicações sobre a área de Recursos Humanos (RH) do Brasil.

Assim, este ensaio teórico, no qual a metodologia utilizada foi uma revisão bibliográfica da literatura referente aos modelos de gestão de pessoas, pretende incitar uma reflexão acerca da utilização, no Brasil, de técnicas importadas para gestão de pessoas - de aplicação pela área de Recursos Humanos. A discussão acontece em torno da premissa de que, devido às diferenças contextuais e socioculturais, as técnicas importadas de gestão de capital humano tendem a ser pouco efetivas no Brasil.

O princípio de que o fator humano é a materialização e reflexo do contexto e do caráter do meio social onde se vive, justifica a atenção dada ao $\mathrm{RH}$, ainda mais sob a perspectiva da sensibilidade do fator humano como o termômetro do choque contextual e sociocultural causado pela base conceitual importada. Ademais, de acordo com Barbosa (2004), a área de RH tem passado por uma crise histórica de identidade, de base epistemológica e de relevância política, o que reforça a arguição, emitida por Thiollent (1987), Burrell e Morgan (1979), Sale et al. (2002), e Rey (2005), de que em todas as ciências, a reflexão sobre os pressupostos teóricos é indispensável. 
Ressalta-se que este trabalho não busca mensurar ou tampouco fornecer uma resposta definitiva às indagações levantadas, mas sim refletir acerca do fato de que a implementação de técnicas importadas de $\mathrm{RH}$ deve ser repensada; bem como refletir a qual destino o processo de importação pode remeter o $\mathrm{RH}$ brasileiro; pois há sistemático subdesenvolvimento teórico $e$ aplicado dessas teorias no Brasil, o que se traduz em resultados pouco efetivos e em uma pouca expressividade da própria área de $\mathrm{RH}$, que, muitas vezes, é relegada ao segundo plano nas organizações.

Além dessa breve introdução, este artigo está organizado em mais sete partes: (1) a primeira seção [fundamento central] busca demonstrar a influência da questão "contexto", o que remete à constatação de que as técnicas importadas de gestão de pessoas, na maioria das vezes, não se adequam às peculiaridades histórico-sociais brasileiras, já que não foram concebidas para ela (MOTTA et al., 2000), ou que a temática do Brasil não é apropriada à sua realidade (SERVA, 1992). A funcionalidade da base importada esbarra sempre na diferença entre o ambiente da nacionalidade onde ela nasce e o ambiente da nação onde será aplicada. Essa mesma diferença é o ponto de apoio e fundamento da questão sobre a eficácia da teoria - diante das diferentes características dos contextos, que de destoantes tornam-se antagônicos, nasce uma incômoda desconfiança sobre o seu funcionamento. (2) A segunda seção busca dar apoio ao pressuposto do estudo ao abordar o produto importado estereotipado e sua necessidade de adaptação. Este momento do trabalho visa destacar o uso irresponsável da importação e alguns motivos para tal ato. (3) A parte seguinte reforça a ideia da exclusividade das características do Brasil, para que, dessa forma, sejam levantadas algumas questões fundamentadas em Thiollent (1987) quando chama a atenção para o fato de que o contexto social confere validade e interpretação no bojo do estudo - a compreensão e abstração dos mais diversos temas são variáveis dependentes da cultura, uma vez que isso remonta a pontos de vista diferentes $e$, por conseguinte, diferenças sistemáticas de categorização e classificação dos atores sociais. De acordo com Fleury et al. (1989), a cultura tem a capacidade de ordenar, atribuir significações e construir identidade. Por conseguinte, (4) a quarta parte apresenta o pano de fundo do contexto brasileiro, que serve para legitimar o "jeitinho brasileiro". (5) Em seguida, é ressaltado, em contraposição com a postura assumida até então - justamente para incitar a reflexão - que há como adaptar o produto importado; ou então que (6) a cópia de técnicas importadas, à luz da teoria do neoinstitucionalismo 
sobre processos isomórficos, pode resultar em inovações não intencionais, cuja eficiência tem caráter constante. (7) Por fim, são tecidas algumas considerações às quais este ensaio teórico permitiu chegar.

\section{Uma Questão de Contexto}

O sentido que o termo contexto assume é o de um ambiente externo à determinada sociedade - classe, grupo, nacionalidade, etc. - dotado de nuances subjetivas que modelam o formato dessa sociedade, tais como modos de pensar, de agir, de se organizar, de relacionamento, etc. Está intimamente relacionado com a designação de cultura, que segundo Fleury et al. (1989) tem a capacidade de ordenar, atribuir significações e construir identidade. Assim como tal, o contexto é um conjunto de elementos - valores, crenças e pressupostos, ritos, rituais, cerimônias, histórias, mitos, tabus, heróis, normas e comunicação - que proporcionam diferentes comportamentos $e$ interpretações, ao mesmo tempo em que influenciam e moldam esses comportamentos e interpretações. Uma sutil diferenciação é que o contexto, para entendimento deste trabalho, se liga a um período de tempo, a um determinado momento histórico - mesmo que seja o presente. Nesse ponto, distingue-se da cultura, considerando que a última é construída ao longo de um processo histórico. Desse modo, o contexto é elemento construtivo da cultura.

A discussão sobre o contexto vivido por determinada sociedade e suas implicações remete à discussão presente no embate da evolução do processo epistemológico em torno da objetividade nas ciências humanas. Entretanto, um parêntese é necessário: a discussão do processo epistemológico é demasiadamente mais profunda e complexa do que a abordada. As ideias aqui apresentadas, embora sejam expressas pelos autores, têm sua relevância relegada a segundo plano ao longo de suas retóricas.

Mannhein (1982) trata da importância do contexto para a construção de um efetivo conhecimento ao discorrer sobre o vínculo entre ciência $e$ ideologia. A ideologia, tratada aqui no âmbito total, refere-se ao modo de uma classe $e^{\mathrm{I}}$ - sociedade - ver o mundo. Cada classe possui uma ideologia, que não é falsa nem verdadeira, mas descreve a composição total da mente de um grupo, i.e., as ideias - por serem função de quem as têm, indicam que estratos sociais diferentes pensam categorias diferentes, através de modos de experiência e interpretação amplamente diferentes. Nesta linha de raciocínio, 
Schaff (1983) fala em fator subjetivo - cultura, contexto histórico, realidade social, etc. Esse autor argumenta que o quadro da realidade de cada classe é diferente, possui peculiaridades que são agentes de diferenciação individual, portanto implica um plano de estereótipos. Corroborando com a construção desse cenário, Weber (1973), com sua ideia de juízos de valor ${ }^{\mathrm{II}}$, afirma que os significados variam de acordo com o caráter da cultura e do pensamento, ou seja, são dotados de subjetividade. A significação torna-se um fenômeno que adquire sentido lógico apenas à uma parte finita [a sociedade]. Neste sentido, os elementos da realidade são valores de uma dada cultura, i.e., um segmento finito e destituído de sentido próprio do mundo, onde o pensamento confere ao indivíduo um sentido e uma significação.

$\mathrm{O}$ aspecto mais discutido pelos autores presentes nesse debate é a influência que o pesquisador sofre da sua sociedade e, portanto, dos contextos nos quais está inserido. A preocupação navega na busca pelo conhecimento, onde o cientista, mesmo inconscientemente, visa atender às exigências $e$ necessidades de seu contexto particular; sua ciência e seu conhecimento são norteados para as respostas das inquietações de suas "classes" específicas, seu aspecto sociocultural. A grande questão levantada é: as proposições e assertivas são universais? Respondem tão eficazmente às indagações de outros contextos?

Ao que parece, a resposta é "não", pois os autores postos buscam constantemente chamar a atenção à tendência de que o conhecimento construído seja fundamentado em proposições e hipóteses em acordo com os caracteres do contexto sociocultural vivido pelo cientista, visto que o processo epistemológico pode ser embasado nas necessidades e anseios de seu momento histórico.

Para nutrir a arguição de que as diferenças entre contextos tendem a inviabilizar o uso de técnicas importadas de gestão, cita-se Motta et al. (2000, p. 11), ao enfocar o mundo empresarial: "se gastam milhões de reais anualmente com a adoção de metodologias e modelos de gestão que não são adequados para a nossa realidade". As distorções temáticas derivadas da diferença de realidade onde foi construída agem como "mecanismo inibidor" das soluções a que se propunham as técnicas originais. Tal cena parece ter sido a fonte de inspiração de Thiollent (1987) quando considerou a importância da adoção da mesma linguagem e do mesmo sistema simbólico onde níveis culturais estão associados à faculdade de abstração e classificação - portanto, desníveis culturais podem ocasionar diferentes enunciações e interpretações. 
Sem conclusões sólidas, Motta et al. (2000) observam fatos empíricos da importação, e afirmam que na implementação de base conceitual estrangeira há sempre a necessidade da adaptação criativa dos "produtos importados". Mais do que isso, advoga-se aqui a necessidade de "substituição" de importações por uma real e efetiva produção nacional.

Nesse momento da retórica torna-se necessário discutir sobre o "produto importado", a fim de fomentar a discussão ao construir zonas de inteligibilidade sobre sua adoção e uso.

\section{Produto Importado}

De acordo com Vergara e Pinto (2001), as referências estrangeiras representam 69,10\% das referências feitas nos estudos brasileiros. Nesse sentido, Bertero e Keinert (1994) afirmam que consumimos, repetimos e divulgamos ideias produzidas fora do país. Esse fato tem dimensão mitológica, visto que, no Brasil, produtos importados soam como sinônimo de "de boa qualidade" (MOTTA; CALDAS, 1997, p. 74). Ao conjugar essa explanação com a visão de Motta et al. (2000), onde as metodologias e modelos importados de gestão não são adequados para a nossa realidade, salta aos olhos um contra-senso: se o produto importado ${ }^{\mathrm{III}}$ não atende à realidade brasileira, por que pesquisadores, gerentes, estudiosos - etc. - se inspiram nas referências [e técnicas] estrangeiras? (MOTTA; CALDAS, 1997).

A falta de adequação percebida nas técnicas de gestão - divergência contextual entre nações (VERGARA; PINTO, 2001) - é um ponto de inflexão que nutre a interrogação sobre a viabilidade da aplicação do produto importado no Brasil. Em verdade, se não se sabe quão bem as técnicas importadas hão de se adequar ao contexto brasileiro (MOTTA et al. 2000), então por que adotar um produto importado diante do inerente risco de não ser satisfatório? Motta e Caldas (1997) acreditam que a adoção é um traço cultural, onde "santo de casa não faz milagre". Por outro lado, Vergara e Carvalho (1995), afirmam que a utilização dos referenciais importados não se deve à adequação deles à realidade sociocultural brasileira, mas sim à influência que têm na formação dos autores brasileiros. Alimentando essa visão, Motta et al. (2000, p. 10) apregoam: 
Um intercâmbio, um MBA, uma "expatriação", um doutorado ou pós-doutorado em uma universidade estrangeira aparece para nós como a melhor maneira de legitimar o executivo ou acadêmico em nosso meio.

Argumentos comuns para legitimação das referências estrangeiras em RH são: sua "idade" (maturidade), posicionamento epistemológico, base empírica, procedimento metodológico, dentre outros fatores [engraçado, não aparece o termo adequação!]. Mas, se olharmos para além do palco [lá nos bastidores], transparece a não preocupação com a funcionalidade dos produtos importados ao contexto brasileiro. Sua capacidade de resultados consistentes fica relegada para segundo plano. Sua adoção é promovida pela "validade", e, por que não dizer, "veracidade" que o fato de ser estrangeiro lhe oferece. Ao se ver uma técnica estrangeira, a princípio, ainda que "não se saiba do que se trata", apenas pelo fato de ser "de fora", muitos a aceitam aprioristicamente como boa e válida.

Resta refletir, para que o súbito ímpeto se revele em insights: a adoção de referências para a construção da base do RH do Brasil perpetuará seu métier na influência e no status que as "references" proporcionam? Esperaremos, sentados, as cenas do próximo capítulo para ver o desfecho?

Os critérios utilizados [conforme explanados] para a adoção de "references", ou a sua falta são os princípios ativos de afirmações, conclusões, arguições, explanações que concluem que técnicas, metodologias e modelos importados de gestão não são adequados para nossa realidade. Como exemplo da problemática de "importar produtos", tomar-se-á por base a administração científica (1885 - 1915), que correspondeu, através da Organização Racional do Trabalho, à necessidade de eficiência que os Estados Unidos padeciam no início do Século XX.

Poder-se-ía imaginar, naquela época, a aplicação dos fundamentos de Taylor - especialização do operário, padronização de métodos e de máquinas, análise do trabalho, estudo de tempos e movimentos - no Brasil? Obviamente que não, afinal em 1888 aconteceu a abolição dos escravos e até os anos 30, verificou-se no Brasil essencialmente a atividade de comercialização e exportação do café; a mão-de-obra, de origem europeia, era especializada, conhecedora e proprietária de suas ferramentas; e o parque industrial era incipiente e iniciava sua expansão e consolidação (FLEURY et al., 1987).

Os problemas da importação indiscriminada foram observados por Barbosa (2005, p. 216), em seu estudo sobre a adoção de modelos de 
competências como prática gerencial de 37 empresas brasileiras instaladas nos estados de Minas Gerais, Rio de Janeiro, Rio Grande do Sul e São Paulo:

Outro ponto que pode ser destacado é a transposição de modelos desenvolvidos nas sedes no exterior, o que reforça a falta de adequação à região onde se encontram instaladas as empresas no Brasil.

Percebe-se, portanto, que a inadequação do produto importado não é mera especulação teórica, mas sim um anseio que emerge na prática cotidiana das organizações. Tal anseio recebe o reforço do "jeitinho brasileiro", que sinaliza uma cultura única e distintiva (MOTTA et al. 2000).

\section{Jeitinho Brasileiro}

Pode-se, então, entender a cultura brasileira como algo distintivo e particular; o povo brasileiro, de maneira geral, mantém ao longo do tempo uma série de características que o distingue dos povos de outras sociedades. (SHIMONISHI; DA SILVA, 2003, p. 3).

Na visão de Motta et al. (2000), os traços marcantes na cultura brasileira são: cordialidade e preferência por relacionamentos pessoais afetivos; malandragem e jeitinho brasileiro; grande distância entre as camadas sociais; não valorização do trabalho manual e valorização dos outros países em detrimento ao Brasil.

Oliveira e Machado da Silva (2001) complementam a caracterização: receptividade a outras raças; hospitalidade; aversão à sistematização do trabalho; favoritismo; paternalismo; ênfase nas relações pessoais; apropriação do público pelo privado; igualdade moral e não jurídica; protecionismo (postura de espectador, orientação pela autoridade externa e transferência de responsabilidade); afeição à paz e à ordem; resistência a mudanças; flexibilidade; improvisação; "fazer vista grossa"; "arranjar um padrinho"; "quebrar o galho"; corrupção; e recursos do poder: "Você sabe com quem está falando" e "Quem você pensa que é, hein?" (BARBOSA, 1992). 
Essa autora expõe os conteúdos da locução "jeitinho": Faz uso da barganha e da argumentação; parte do pressuposto igualitário; é acessível a todos da sociedade; não depende de laços profundos, mas sim de atributos da personalidade; pode começar e terminar anonimamente; suscita reciprocidade positiva difusa; não possui qualquer situação social que seja a sua simétrica inversa, dentre outros.

O jeitinho, portanto, é legítimo e explícito como forma de ação social, constituindo-se um dos traços que nos define como país e como brasileiros. Em outras palavras, o jeitinho torna-se um elemento de identidade social a partir do momento que é entendido como um dado da realidade brasileira, definindo, via significação paradigmática, o que é o Brasil enquanto país e o que é o seu povo.

O conceito de identidade social, segundo Barbosa (1992, p. 125-126), é:

Diferentes formas de percepção que se constroem no interior das sociedades e que norteiam as relações entre os grupos e das pessoas enquanto membros de um grupo. [...] As identidades são, portanto, construções culturais. São categorias que funcionam como sistema codificador de uma vasta teia de relações. É um sistema de classificação que separa e ordena uma população numa série de categorias que se opõem e complementam.

A identidade tem reflexos sobre o grupo e, por conseguinte, sobre o todo social, uma vez que está ligada à construção de estereótipos e do caráter grupal. Não há como dissociá-la das visões de mundo de um determinado grupo (podendo ser grupo de trabalho, classe, sociedade, nação, etc.), das experiências comuns desse grupo, bem como da sua ótica etnológica, construção de conhecimento, comportamento, etc. (VERGARA; PINTO, 2001).

Para fornecer luz às inquietações, recorre-se novamente à analogia com o norte-americano - no entanto, há de se justificar seu uso: a comparação é feita com os Estados Unidos pelo fato, de acordo com Vergara e Pinto (2001), da literatura brasileira sofrer maior influência de lá. Ao observar a identidade social norte-americana, em conformidade com Barbosa (1992), percebe-se a inexistência de escolha, uma vez que o sistema gira em torno de um único eixo ideológico; a postura é igualitária, individualista e englobadora, constituindo a linha de conduta. Em contrapartida, a identidade brasileira é 
caracterizada por "um universo social permanentemente relativista em termos de valores. Aqui, esses não teriam uma posição fixa e determinada em um eixo ideológico central [...]" (BARBOSA, 1992, p.76). No padrão norteamericano nota-se claramente o cumprimento das regras e obediência à formalização e à estrutura determinística; cujo mecanismo de organização apoia-se na base formal e na estrutura construída - ênfase no individualismo, na posição e na eficácia. $\mathrm{O}$ jeitinho brasileiro, por sua vez, ignora qualquer desigualdade de conteúdo social, buscando um conteúdo moral igualitário onde todos participam. Burlando a tônica na posição, é um rito aglutinador e igualitário - "meu irmão, meu amigo", "companheiro", "gente boa", "minha tia" (BARBOSA, 1992, p. 75).

A gritante diferença entre o "jeito" brasileiro e o norte-americano, revelada por traços culturais marcantes e específicos em cada identidade social apresentada (traços, estes, distintos e que, em alguns casos, são antagônicos) apoia o axioma ${ }^{\mathrm{IV}}$ de que, devido às diferenças contextuais e socioculturais, a técnica importada de gestão de $\mathrm{RH}$ tende a ser inócua no Brasil. Uma sistemática de gerir pessoas norte-americanas, por exemplo, não considera a "malandragem do brasileiro" (DA MATTA, 1983), ou o traço cultural de "não dizer não" - será mesmo que um modelo de "HR" (human resources), que não foi criado para gerir pessoas cuja identidade social denota "malandragem", não valorização do trabalho manual, ênfase nas relações pessoais, resistência a mudanças, "fazer vista grossa", "arranjar um padrinho", "quebrar o galho", paternalismo, patrimonialismo, dentre outros, poderia ser aplicado no Brasil?

A acuidade do contexto - somada à identidade do jeitinho brasileiro é um indicativo de que o desempenho do produto importado está fadado a ser ineficaz ou pouco expressivo, afinal a importação traz a reboque o inerente risco de uma técnica enviesada em um determinado contexto sociocultural destoante do contexto brasileiro, portanto procuram se ajustar e suprimir as lacunas daquele viés e não deste último.

A chave para reflexão sobre a pertinência da implantação de produtos importados é entender o contexto brasileiro como único e diferente do contexto de qualquer outro país. Dessa forma, atenção deve ser dada ao patrimonialismo, pois este é a base e o fundamento das relações sociais no Brasil - o patrimonialismo está acima do racional, ou do irracional. O contexto brasileiro se constrói, se desenvolve e se molda sobre o plano de fundo patrimonialista. O modelo importado adotado pode ser escolhido 
pelo autoritarismo e bel-prazer, natural do patrimonialismo, do "dono do poder", sem que se leve em consideração a adequação e características desse modelo. Metaforicamente falando, o dono do poder deve ser entendido como o maestro que rege a orquestra "Brasil". Ele é quem determina as ações dos diversos atores - os músicos da metáfora.

\section{Patrimonialismo}

Sobre a sociedade, acima das classes, o aparelhamento político - uma camada social - impera, rege e governa, em nome próprio, num círculo impermeável de comando. Esta camada muda e se renova, mas não representa a nação [...] (FAORO, 1989, p. 737).

O patrimonialismov refere-se ao monopólio do poder por um único detentor - pessoa, assembleia, comitê, junta ou um partido - que usufrui da "vontade da maioria" para benefício próprio. Em outras palavras, o Estado é administrado pela classe política - minoritária - que o subjuga à suas vontades, assim o Estado acaba se tornando patrimônio do governante. A administração pública assume a extensão de patrimônio pessoal patrimonialismo pessoal se converte em patrimonialismo estatal - onde um quadro dirigente organiza a esfera econômica, política e financeira em função dos objetivos próprios. A nação, portanto, é centralizada em uma unidade, em que a minoria governa sempre.

De D. João I até os dias de hoje, o regime dos donos do poder, sem pretender dominar a totalidade da vida socioeconômica, participa na formação das decisões estatais, via seus mecanismos de controle e regulamentação; e comanda o ramo civil e militar da administração. Em toda a história brasileira atuou em causa própria, servida dos instrumentos políticos derivados da posse do aparelho estatal. "Em lugar de integrar, comanda; não conduz, mas governa" (FAORO, 1989: p. 743). Ao longo da trajetória histórica do Brasil, via tradicionalismo, o domínio patrimonial, constituído pelo estamento, apropriou as oportunidades econômicas, o desfrute dos bens, das concessões, dos cargos; numa constante confusão entre o setor público e o privado, entre o setor pessoal e o setor fiscal. 
Os "donos do poder" não são caracterizados como uma classe - pois assim extrapolaria seu objetivo econômico e político - nem mesmo uma elite, visto que não estão sujeitos à escolha, à renovação, à mudança, ao movimento circular. Esta camada muda e se renova pela força do tempo - substitui moços por velhos, aptos por inaptos; e sempre cunha e imprime seus valores aos novatos.

\section{6 "Pra” não Dizer que não Falei da Tropicalização}

É importante ressaltar o termo "tropicalização", que significa, em poucas palavras, adaptar modelos, teorias e metodologias estrangeiras às condições brasileiras. Consiste em adequá-los e ajustá-los às características brasileiras; causar-lhes transformações que visam viabilizar sua utilização (funcionamento) ao nosso contexto; torná-los pertinentes, úteis e eficientes. Em uma linguagem tipicamente brasileira, dir-se-ía "dar um jeitinho aqui, fazer uma "gambiarrazinha" ali para pôr o modelo estrangeiro para funcionar". Segundo a perspectiva do patrimonialismo, seria reinterpretá-los de acordo com a sensibilidade e os interesses dos donos do poder.

De volta à analogia com o norte-americano, tropicalizar é transformar um modelo de HR em RH, i.e., tentar tornar o segundo "tão eficaz" quanto o primeiro ao ajustar aquele às peculiaridades socioculturais (identidade) brasileiras. Na prática, equivale a fazer uso do modelo de $H R$, incorporandoo à malandragem brasileira, à desvalorização do trabalho manual, à resistência a mudanças, ao "quebrar o galho", à cultura de "não dizer não", etc., sem perder de vista os interesses de quem detêm o poder.

A tropicalização é fato ou ficção?

\section{Isomorfismo - 0 “Primo Rico” da Tropicalização}

O isomorfismo (etnomologia: grego iso (igual) e morphos (forma)), sob o enfoque neoinstitucionalista, significa a aquisição de um formato organizacional, considerado legítimo em um determinado ambiente institucional (DIMAGGIO; POWELL, 1991), que induzem as organizações a selecionarem a forma mais adaptada à sua sobrevivência (HANNAN; 
FREEMAN, 1977). O fio condutor da explicação seria a ideia de que as organizações assumem características estruturais semelhantes (SCOTT, 1995) ao longo dos seus ciclos de vida. Nos estágios iniciais, conforme descrevem Dimaggio e Powell (1991), verifica-se uma diversidade considerável em termos de abordagem $e$ forma; as quais caminham - através de um impulso inexorável ao longo do tempo - em direção à homogeneização [isomorfismo], que, por sua vez, decorre da exclusão de formas não-ótimas, ou dos tomadores de decisões nas organizações, que aprendem respostas adequadas e ajustam seus comportamentos de acordo com elas.

Meyer (1979) e Fennel (1980) defendem a existência de dois tipos de isomorfismo: o competitivo e o institucional. Entretanto, segundo Dimaggio e Powell (1991), o conceito de isomorfismo institucional apresenta-se como uma ferramenta útil para uma maior compreensão da vida organizacional moderna. Tal conceito possui três mecanismos responsáveis pelas mudanças isomórficas institucionais, são eles: o isomorfismo coercitivo, derivado de influências políticas e do problema da legitimidade; o isomorfismo mimético, advindo de respostas padronizadas à incerteza; $e$ o isomorfismo normativo, associado à profissionalização. É válido ressaltar que a tipologia apresentada por Dimaggio e Powell (1991) é puramente analítica, pois, no plano empírico, os três tipos muitas vezes encontram-se mesclados.

As similaridades entre as organizações, i.e., o isomorfismo, deriva, em grande parte, da incerteza em relação ao ambiente empresarial - o que culmina na imitação de modelos, metodologias e técnicas de sucesso de outras empresas como fonte de redução de incerteza. Assim, quando as metas da organização são ambíguas ou o ambiente gera uma incerteza simbólica, as organizações muitas vezes são tentadas a tomar outras organizações como modelo.

Um desdobramento curioso advindo do processo mimético seria o incremento das metodologias, técnicas e modelos, que, conforme destaca Alchian (1950), segundo o qual enquanto certamente há aqueles que inovam conscientemente, há aqueles que, em suas tentativas imperfeitas de imitar os outros, inovam inconscientemente por meio da aquisição involuntária de atributos únicos inesperados ou não procurados, os quais, sob as circunstâncias correntes, se provam parcialmente responsáveis pelo sucesso. Como um dos mais representativos exemplos de isomorfismo mimético transnacional, Dimaggio e Powell (1991) apresentam o caso da modernização japonesa, no final do Século XIX, que tomou como modelo para suas novas 
iniciativas governamentais exemplos do Ocidente aparentemente bem sucedidos. Dessa forma os novos exércitos, polícia e cortes de justiça do Japão tiveram como inspiração as respectivas instituições na França; para a Marinha e os Correios a inspiração foi britânica; e para o setor bancário como para a educação artística, tomou-se como base as instituições norte-americanas.

Contudo, a imitação pode se tornar um processo ritualístico, onde as mudanças assumem o papel de legitimação, ou seja, as organizações tendem a tomar como modelo outras organizações que julguem ser mais legítimas ou bem sucedidas. Nesse sentido, a adoção de determinados arranjos estruturais pode estar mais relacionado aos processos miméticos - puramente o ato de imitar como fonte de segurança frente à incerteza - do que à busca de um maior nível de eficiência.

\section{Considerações Finais}

Afinal, a importação de técnicas de gestão de pessoas é um problema ou uma solução? A identidade, como sistema codificador e construtor de estereótipos, acaba por determinar específicos modos de pensar, de agir, de se relacionar, etc., bem como de compreender e abstrair diversas temáticas, findando na construção de conhecimentos bem específicos, relacionados ao contexto estruturado pela identidade do grupo, ou sociedade. Dessa forma, pode ser problemático utilizar uma técnica de gestão de pessoas - por mais bem sucedida que seja - que foi criada com base em experiências, valores, crenças, pressupostos, ritos rituais, histórias, mitos, tabus e normas, diferentes das experiências, valores, crenças [...] de um grupo diferente do grupo de pessoas onde serão aplicadas. São comportamentos e pontos de vistas diferentes, que requerem tratamentos e categorizações diferentes. Nesse sentido, qualquer técnica de gestão, que, logicamente, atende a um determinado padrão cultural, é, por natureza, determinística e utilitarista visivelmente restrita - ao berço onde nascera.

Tal explanação é nutrida por Motta et al. (2000) quando afirma que as metodologias, modelos e técnicas importados não são adequados à nossa realidade. O que pensar quando Vergara e Pinto (2001) constatam que a literatura brasileira é baseada em autores estrangeiros? Seria um indício de que a importação de técnicas de gestão de pessoas é uma fonte de soluções? Não! Afinal é fato visível a falta de adequação de tais técnicas - vide a 
apreciação empírica de Barbosa (2005). A insistência pela adoção dessas técnicas não se dá em decorrência dos resultados da prática, mas sim, conforme ressalta Motta et al. (2000), pela legitimação que as técnicas proporcionam.

$\mathrm{O}$ isomorfismo mimético e a tropicalização dão fôlego a dúvidas que vinham sendo desmanteladas pelo posicionamento assumido ao longo da retórica. Neste ponto da arguição, portanto, é preciso algumas considerações. Sobre a tropicalização, acreditamos que esta não é eficiente ao adequar o produto importado às demandas das peculiaridades do contexto do jeitinho brasileiro - o que nos leva a tal perspectiva são as observações empíricas da referida inadequação, feitas por Motta et al. (2000) e Barbosa (2005). Em relação ao isomorfismo mimético, consideramos, a priori, a seguinte questão: a importação de técnicas de gestão de pessoas leva à ineficiência ou a soluções inovadoras? A importação de tais técnicas caminha numa via de duas mãos, ou seja, pode tanto levar à adoção de modelos ineficientes frente às peculiaridades brasileiras, quanto pode até gerar soluções inovadoras. Todavia, temos por crença de que a via da ineficiência, ao que parece, é mais comum no cenário da importação dos modelos estrangeiros, principalmente diante da despreocupação com a adequação ao contexto discutida ao longo do texto.

Não negamos que em alguns casos tanto a tropicalização quanto o isomorfismo podem proporcionar bons resultados - no sentido de adaptar eficientemente um produto importado. Entretanto, defendemos que esta é uma cena rara - portanto, não podemos ficar sentados esperando as cenas do próximo capítulo.

Deve ser lembrado que a falta de preocupação com a funcionalidade dos produtos importados e seu excessivo uso como forma de legitimar técnicas $e$ teorias pode ter efeito reverso e acabar deslegitimando toda a produção científica brasileira de técnicas de gestão de pessoas, ao longo de sua "carreira"; afinal, essa produção está sendo construída por fundamentos estéreis. A inspiração em base conceitual que não equaciona problemas e, tão pouco, responde às demandas, incorrerá na descrença da produção nacional. Já é verificado sistemático subdesenvolvimento teórico e aplicado das técnicas para gerir pessoas no Brasil, as quais possuem resultados pouco efetivos; culminando em pouca expressividade da área de $\mathrm{RH}$ do Brasil, que é relegada ao segundo plano nas organizações. A adoção de técnicas importadas para gerir pessoas teria alguma relação com esse fato? 
Este trabalho não pretendeu ser um movimento nacionalista ("Pra frente Brasil!"), nem afirmar que a construção de base conceitual caseira é a solução milagrosa para os problemas vivenciados pelo $\mathrm{RH}$ brasileiro. A reflexão é o primeiro passo para a mudança; dessa forma, analisar a importação de base conceitual de $\mathrm{RH}$ - teoria, técnicas e metodologias - está no âmago do cotidiano dessa ciência, como no de qualquer outra ciência, uma vez que é estritamente importante para a decisão de novos rumos, ou seja, para a consecução de identidade, de base epistemológica e de política de qualquer área - e não apenas na de Recursos Humanos.

\section{Importation of Techniques of Human Resources: problem or solution?}

\section{Abstract}

Starting of assumption that the Brazilian literature in general, but mainly the area of Human Resources is based on foreign authors, the aim this paper is promote a reflection about the efficiency of the use of techniques imported from people management in Brazil. The questions revolve around the difference between sociocultural contexts and the implications of the adoption of the basic foreign (stereotype of his birthplace) in the Brazilian context, where the "jeitinho brasileiro" is considered unique and exclusive. This environment happened with the "patrimonialismo" as scenario. There is also the possibility of "tropicalização" these models by isomorphism. However, it appears that due to differences contextual and sociocultural leads the techniques of import management to be less effective in Brazil.

Key-words: Human Resources. Importation of management models. Tropicalização. Isomorphism.

\section{Referências}

ALCHIAN, A. Uncertainty, evolution and economic theory. Journal of Political Economy, v. 58, p. 211-221, 1950.

BARBOSA, L. O jeitinho brasileiro. Rio de Janeiro: Campus, 1992. 
BARBOSA, A. C. Q. A produção acadêmica em recursos humanos no Brasil: fato ou ficção? RAE Eletrônica, v. 3, n. 2, julho/dezembro, 2004.

BARBOSA, A. C. Q. Competências no Brasil: um olhar sobre os modelos organizacionais de grandes empresas de Minas Gerais, Rio de Janeiro, Rio Grande do Sul e São Paulo. Belo Horizonte: UFMG/CNPq, 2005. Relatório de Pesquisa.

BERTERO, C. O; KEINERT, T. A evolução da análise organizacional no Brasil (1961-1993). São Paulo: Revista de Administração de Empresas (34) 3: 81-90, 1994.

\section{BURRELL, G.; MORGAN, G. Sociological paradigms and}

organizational analyzis. London: Heinemann Educational Books, 1979.

CARVALHO, C. A.; GOULART, S.; VIEIRA, M. F. A inflexão conservadora na trajetória histórica da teoria institucional. In: Encontro Nacional De Programas De Pós-Graduação Em Administração, 2004, Curitiba. Anais ... Rio de Janeiro: ANPAD, 2004.

DAMATTA, R. Carnavais, Malandros e Heróis. Rio de Janeiro: Zahar, 1983.

DIMAGGIO, P. J.; POWELL, W. W. The iron cage revisited: institutional isomorphism and collective rationality. In: POWELL, W. W.; DIMAGGIO, P. J. (Eds.). The new institutionalism in organizational analysis. London: The University of Chicago Press, 1991. p. 63-82.

FAORO, R. Os donos do poder. São Paulo: Hucitec, 1994.

FENNEL, M. L. The effects of environmental characteristics on the structure of hospital clusters. Administrative Science Quarterly, v. 25, n. 3, p. 484-510, 1980.

FLEURY, M. T. L. et al. Cultura e poder nas organizações. São Paulo: Atlas, 1989.

FLEURY, M. T. L. et al. Relações de trabalho e políticas de gestão: uma história das questões atuais. In: Anais... Canela: Anpad, 1992.

HANNAN, M. T.; FREEMAN, J. H. The population ecology of organizations. American Journal of Sociology, v. 82, n. 5, p. 929-64, 1977. 
MANNHEIN, K. Ideologia e utopia. Rio de Janeiro: Zahar Editores, 1983.

MEYER, J. W.; HANNAN, M. T. National Development and the World System: Educational, Economic, and Political Change. Chicago: The University of Chicago Press, 1979.

MEYER, J. W.; ROWAN, B. Institutionalized organizations: formal structure as myth and ceremony. American Journal of Sociology, v. 83, n. 2, p. 340363, 1977.

MOTTA F. C. P.; ALCADIPANI, R.; BRESLER, R. B. O estrangeiro e o mundo organizacional. In: Anais do I Eneo. Curitiba: Anpad, 2000.

MOTTA, F. C. P.; CALDAS, M. Cultura Organizacional e Cultura Brasilera. São Paulo: Atlas, 1997.

OLIVEIRA, P. T.; MACHADO-DA-SILVA, C. L. Características culturais nacionais em organizações industriais do setor alimentício paranaense. Organizações \& Sociedade, v. 8, n. 22, p. 27-48, set./dez. 2001.

POPPER, K. A lógica da pesquisa científica. São Paulo: Cultrix, 1972.

RAMOS, G. Administração e Contexto Brasileiro. 2. ed. Rio de Janeiro: FGV, 1983.

REY, F. G. Pesquisa qualitativa e subjetividade: os processos de construção da realidade. São Paulo: Pioneira Thomson Learning, 2005.

SALE, J. E. M.; LOHFELD, L. H; BRAZIL, K. Revisiting the quantitativequalitative debate: implications for mixed-methods research. Quality \& Quantity. v. 36, p. 43-53, 2002.

SCHAFF, A. História e verdade. São Paulo: Martins Fontes, 1983.

SCOTT, W. R. Institutions and Organizations. Thousand Oaks: Sage, 1995.

. Organizations, rational, natural and open systems. 4. ed., New Jersey: Prentice Hall, 1995.

SERVA, M. A importação de metodologias administrativas no Brasil — Uma análise semialógica. Rio de Janeiro: Revista de Administração Pública. 26(04):128-144, 1992. 
SHIMONISHI J. S.; DA SILVA C. L. Características Culturais Brasileiras e Atividades Gerenciais em Agências Bancárias: estudo comparativo de casos. In: Anais XXVII ENANPAD. Atibaia - São Paulo: Anpad, 2003.

THIOLLENT, M. Crítica metodológica, investigação social e enquete operária. São Paulo: Polis, 1987.

TAYLOR, F. W. Princípios de administração científica. São Paulo: Atlas, 1987.

TONELLI, M. J.; CALDAS, M. P. Produção acadêmica em recursos humanos na década de 90: uma análise metateórica da pesquisa brasileira em periódicos e nos anais do EnANPAD. São Paulo: FGV EAESP/GV Pesquisa, 2004. Relatório de Pesquisa.

VERGARA, S.; CARVALHO, D. Nacionalidade dos Autores Referenciados na Literatura sobre Organizações. In: Anais XIX ENANPAD. João Pessoa: Anpad: 170-188. 1995.

VERGARA, S.; PINTO, M. C. S. Nacionalidade das referências teóricas em análise organizacional: um estudo das nacionalidades dos autores referenciados na literatura brasileira. In: Encontro Anual da Associação dos Programas de Pós-Graduação em Administração, 1, 2000, Curitiba. Anais... Curitiba: Anpad, 2000.

WEBER, M. Economy and Society: an outline of interpretative sociology. New York: Bedminster, 1968.

. Ensayos sobre metodología sociológica. Buenos Aires: Amorrotu Editores, 1973.

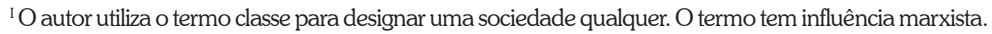

"Significados subjetivos que um indivíduo constrói a partir de suas crenças, valores, percepções etc. O processo cognitivo e, portanto, epistemológico é formado a partir dos aspectos socioculturais desse indivíduo.

IIIPode figurar-se como base teórica, teoria, técnicas, metodologias e/ou métodos estrangeiros. Contudo, para consecução do objetivo deste trabalho, deve ser visto como técnicas importadas de gestão de pessoas.

${ }^{\text {IV }}$ Axioma, para fins deste trabalho, assume o sentido de uma sentença que não é provada ou demonstrada, mas necessária para a construção de conhecimento.

${ }^{\vee}$ A discussão sobre o patrimonialismo baseia-se em Faoro (1989) - obra Os donos do poder.
} 